\title{
Pengaruh Tingkat Pendidikan Formal Orang Tua terhadap Prestasi Belajar Mahasiswa Program Studi Bimbingan dan Konseling IKIP-PGRI Pontianak Tahun Akademik 2014/2015
}

\author{
Eli Trisnowati
}

Program Studi Bimbingan dan Konseling, IKIP-PGRI Pontianak

\begin{abstract}
This study uses fieldwork (Field Research), with a population of 150 students / $i$ Prodi Counseling third semester of the academic year 2014/2015, which was divided into two groups: the experimental group (students who are high school level of education their parents / S1) totaled 30 people, and the control group (students whose parents education level SD) numbered 30 people. The results showed that no significant relationship between the level of formal education of parents on student achievement guidance and counseling courses Teachers' Training College PGRI Pontianak. This is shown by the price of " $t$ " arithmetic (0.487) is less than the price of " $t$ " of criticism, both at the 5\% significance level (2.01) as well as on the significance of $1 \%$ (2.68). This means the hypothesis Alternative (Ha) rejected that there is significant between formal education level of parents on student achievement, and on the contrary hypothesis Nil (Ho) filed unacceptable that no significant relationship between the level of formal education of parents on achievement student learning. So it can be concluded that the level of education among students high school parents with a college education level of parents $S D$ no difference in academic achievement.
\end{abstract}

Keyword: education level, academic achievement

Copyright (C) 2017 IICET (Indonesia) - All Rights Reserved

Indonesian Institute for Counseling, Education and Theraphy (IICET)

\section{PENDAHULUAN}

Pendidikan yang diselenggarakan di Indonesia merupakan realisasi dari salah satu didirikannya Negara Indonesia, yaitu mencerdaskan kehidupan bangsa. Menurut Herman, T. (2007) menjelaskan bahwa pendidikan memiliki peranan yang sangat sentral dalam meningkatkan kualitas sumber daya manusia. Selanjutnya menurut (Gunawan, H. 2012; Indonesia, P. R. (2003) juga menegaskan bahwa pendidikan nasional berfungsi mengembangkan dan membantu watak serta peradaban bangsa yang bermartabat dalam rangka mencerdaskan bangsa, serta bertujuan untuk berkembangnya potensi peserta didik agar menjadi manusia yang beriman.

Dalam upaya mencerdaskan kehidupan itulah diselenggarakan pendidikan nasional yang berdasarkan Pancasila sebagai pandangan hidup bangsa. Sehubungan dengan pendidikan yang ditetapkan dalam Undangundang Republik Indonesia No 20 Tahun 2003 tentang Sistem Pendidikan Nasional Bab II, Pasal 3 yaitu sebagai berikut :

"Pendidikan Nasional berfungsi mencerdaskan mengembangkan kemampuan dan membentuk watak serta peradaban bangsa yang bermartabat dalam rangka mencerdaskan kehidupan bangsa, bertujuan 
untuk berkembangnya potensi peserta didik agar menjadi manusia yang beriman dan bertakwa kepada Tuhan yang Maha Esa, berakhlak mulia, sehat, berilmu, cakap, kreatif, mandiri, dan menjadi warga negara yang demokratis serta bertanggung jawab".

Dalam GBHN (ketetapan MPR No. IV/MPR/1978) berkenaan dengan pendidikan dikemukakan antara lain: "Pendidikan berlangsung seumur hidup dan dilaksanakan di dalam lingkungan rumah tangga, sekolah dan masyarakat. Karena itu, pendidikan menjadi tanggung jawab keluarga, masyarakat dan pemerintah". Berdasarkan hal itu, maka di negara Indonesia ada tri pusat pendidikan yang meliputi keluarga, sekolah dan masyarakat. Istilah tiga lingkungan pendidikan itu dikenal dengan pendidikan formal, pendidikan informal dan pendidikan non-formal.

Menurut Hamzah, N. (2015) pendidikan merupakan pemberi corak dalam kehidupan manusia. Meningkatkan pendidikan kearah yang lebih baik merupakan tanggung jawab bersama, tidak hanya dibebankan kepada pemerintah semata tetapi juga terhadap orang tua dan masyarakat Mulyani, E. (2012). Menurut Nasional, D. P. (2003) menjelaskan bahwa kegiatan pendidikan hakikatnya berlangsung sepanjang hayat atau seumur hidup baik dari keluarga, masyarakat san sekolah dapat berupaya pembelajaran bimbingan pengajaran dan latihan. Selanjutnya Budi, B. S. (2014) menegaskan dasar dari pendidikan seumur hidup bertitik tolak atas keyakinan, bahwa proses pendidikan berlangsung selama manusia hidup, baik di sekolah maupun di luar sekolah.

Mawarsih, S. E., \& Hamidi, N. (2013) mengemukakan bahwa keluarga memilki peranan yang sangat tinggi dalam pendidikan anak karena dalam keluargalah anak mendapatkan pendidikan pertama. Selanjutnya Akbar, M. A. (2015) menjelaskan bahwa orang tua memiliki peranan penting terhadap pendidikan anak. Kemudian Gunarsa, S. D. (2008) juga menjelaskan orang tua yang memiliki tingkat pendidikan tinggi biasanya memiliki cita-cita yang tinggi pula terhadap pendidikan anak-anaknya. Mereka menginginkan pendidikan anak-anaknya lebih tinggi atau setidaknya sama dengan pendidikan orang tua mereka.

Menurut Wildayati, I. A. (2012) cita-cita dan dorongan ini akan mempengaruhi sikap dan perhatiannya terhadap keberhasilan anak-anaknya di sekolah. Melalui proses pendidikan yang pernah dijalaninya orang tua yang berpendidikan tinggi akan memiliki wacana pengetahuan, keterampilan yang luas dan kemampuan emosi yang dapat membantu memecahkan berbagai permasalahan yang dihadapi oleh anak, baik itu yang berkaitan dengan pergaulan anak ataupun pelajaran di sekolah. Hal itu tentunya akan berbeda sekali dengan orang tua yang memiliki latar belakang pendidikan yang rendah. Sebab kapasitas pengetahuan yang dimiliki, sehingga kemampuan dalam mengasuh dan juga mendidik anak, bisa menjadi kurang baik walaupun tidak semua orang tua yang berpendidikan rendah dapat dikatakan demikian, sebab ada juga kemungkinan orang tua yang seperti itu dapat juga bersifat positif terhadap pendidikan anaknya, namun hal tersebut belumlah cukup ditunjang dengan kemampuan pendidikan yang memadai dan sesuai dengan kebutuhan anak sehingga kurang menunjang pula dalam keberhasilan pendidikan anak Suryoputro, A., Ford, N. J., \& Shaluhiyah, Z. (2006).

Melihat dari kenyataan bahwa keluarga yang orang tuanya berpendidikan rendah atau tidak berpendidikan, ternyata berhasil dalam mendidik anaknya dan sebaliknya ada keluarga yang orang tuanya berpendidikan tinggi ternyata kurang berhasil dalam mendidik anaknya. Keberhasilan mendidik anak disini adalah anak-anak yang disekolahnya pintar dan memperoleh prestasi yang baik. Bertitik tolak dari fenomena di ataslah yang mendorong peneliti untuk meneliti dengan judul "Pengaruh Tingkat Pendidikan Formal Orang Tua Terhadap Prestasi Belajar Mahasiswa Bimbingan dan Konseling Semester III IKIP PGRI Pontianak Tahun AKademik 2014/2015". 


\section{METODOLOGI}

Metode yang digunakan dalam penelitian ini adalah metode penelitian lapangan (Field Research) dimana peneliti melakukan penelitian langsung ke lapangan untuk mencari data dari responden. Populasi dalam penelitian ini adalah mahasiswa/i Prodi Bimbingan dan Konseling semester III tahun akademik 2014/2015. Terdiri dari 3 kelas dengan jumlah keseluruhan 150 mahasiswa. Sampel diambil secara acak dengan purposive sampling yaitu mengambil sampel berdasarkan ciri-ciri khusus yang telah ditentukan. Dari 3 kelas yang terdiri 150 mahasiswa adalah 60 orang, dibagi menjadi 2 kategori atau kelompok yaitu kelompok eksperimen (mahasiswa yang tingkat pendidikan orang tuanya SMA/S1) berjumlah 30 orang, dan kelompok kontrol (mahasiswa yang tingkat pendidikan orang tuanya SD) berjumlah 30 orang.

Teknik pengumpulan data yang digunakan dalam penelitian ini adalah teknik komunikasi tidak langsung. Alat pengumpul data yaitu menggunakan observasi, angket atau kuesioner dan studi dokumenter. Teknik analisis data dalam penelitian ini menggunakan teknik analisa komparasional, yaitu teknik analisa kuantitatif atau salah satu teknik yang analisa statistiknya dapat dipergunakan untuk menguji hipotesa mengenai ada tidaknya perbedaan antar variabel yang sedang diteliti. Jika perbedaan itu memang ada, apakah meyakinkan (signifikan), atau perbedaan itu hanya terjadi secara kebetulan (by chance).

\section{HASIL DAN PEMBAHASAN \\ Hasil Penelitian}

Berdasarkan pada deskripsi dan analisis data, maka dapat diberikan interpretasi sebagai berikut:

1. Tidak ada pengaruh yang signifikan antara tingkat pendidikan formal orang tua terhadap prestasi belajar mahasiswa program studi Bimbingan dan Konseling IKIP PGRI Pontianak. Ini ditunjukan dengan harga " $\mathrm{t}$ " hitung $(0,487)$ lebih kecil dari pada harga " $\mathrm{t}$ " kritik, baik pada taraf signifikansi $5 \%$ $(2,01)$ maupun pada signifikansi $1 \%(2,68)$.

2. Dengan lebih kecilnya harga "t" hitung dari pada harga " $\mathrm{t}$ " kritik baik pada taraf signifikansi $5 \%$ dan $1 \%$, berarti Hipotesa Alternatif (Ha) di tolak yaitu adanya pengaruh yang signifikan antara tingkat pendidikan formal orang tua terhadap prestasi belajar mahasiswa, dan sebaliknya Hipotesa Nihil (Ho) yang diajukan dapat diterima yaitu tidak adanya pengaruh yang signifikan antara tingkat pendidikan formal orang tua terhadap prestasi belajar mahasiswa. Dari penelitian ini didapatkan bahwa antara mahasiswa yang tingkat pendidikan orang tuanya SMA dengan mahasiswa yang tingkat pendidikan orang tuanya SD tidak terdapat perbedaan dalam prestasi belajarnya.

\section{Pembahasan}

Setelah data-data yang ada diidentifikasikan dan dianalis ternyata mahasiswa yang tingkat pendidikan orang tuanya SMA sama dengan mahasiswa yang orang tuanya berpendidikan SD. Ini dapat dilihat dari hasil perhitungan uji statistik dengan menggunakan rumus uji " $t$ " diperoleh hasil sebesar 0,487, setelah dikonsultasikan dengan nilai " $t$ " pada taraf signifikansi 5\% (2,01) dan taraf signifikansi $1 \%(2,68))$ dan ternyata diketahui bahwa hasil "t" hitung lebih kecil dari pada nilai " $\mathrm{t}$ " kritik. Hal ini berarti bahwa Hipotesa Alternatif ( $\mathrm{Ha}$ ) yang berbunyi "adanya pengaruh yang signifikan antara tingkat pendidikan formal orang tua terhadap prestasi belajar mahasiswa" ditolak. Sedangkan Hipotesa Nihil (Ho) yang berbunyi "tidak adanya pengaruh yang signifikan antara tingkat pendidikan formal orang tua terhadap prestasi belajar mahasiswa" diterima.

Dari hasil di atas dapat disimpulkan bahwa antara mahasiswa yang tingkat pendidikan orang tuanya SMA dengan mahasiswa yang tingkat pendidikan orang tuanya SD tidak adanya perbedaan dalam prestasi belajarnya. Telah diketahui bahwa mahasiswa yang tingkat pendidikan orang tuanya lebih tinggi sudah pasti akan memiliki prestasi yang baik pula, namun tidak menutup kemungkinan bahwa mahasiswa yang tingkat pendidikan orang tuanya rendah pun akan berprestasi pula. Tergantung dari motivasi mahasiswa itu sendiri dan peran serta orang tua dalam mendidik dan membimbing belajar anaknya. Mengingat bahwa mahasiswa 
sebagian besar tidak tinggal bersama orang tua, maka tidak mengherankan jika antara mahasiswa yang tingkat pendidikan orang tuanya SMA dengan mahasiswa yang tingkat pendidikan orang tuanya SD tidak terdapat perbedaan dalam prestasi belajar mereka. Dalam hasil skor angket yang didapat menunjukan bahwa mahasiswa yang tingkat pendidikan orang tuanya SMA memiliki skor yang lebih tinggi berjumlah 2608 dibanding mahasiswa yang tingkat pendidikan orang tuanya SD yang jumlahnya 2571.

\section{SIMPULAN}

1. Tingkat pendidikan formal orang tua mahasiswa/i program studi bimbingan dan konseling semester III Tahun Akademik 2014/2015 di IKIP PGRI Pontianak berada pada tingkat menengah. Hal ini ditunjukan tingkat pendidikan formal orang tua rata-rata sampai tingkat SMA.

2. Mayoritas nilai rata-rata prestasi belajar mahasiswa/i program studi bimbingan dan kosneling semester III Tahun Akademik 2014/2015 di IKIP PGRI Pontianak termasuk dalam tingkat kualifikasi cukup dan tinggi, berada pada rentangan skor 60-90.

3. Tingkat pendidikan formal orang tua berpengaruh secara signifikan terhadap prestasi belajar mahasiswa/i Prodi Bimbingan dan Konseling Semester III Tahun Akademik 2014/2015 di IKIP PGRI Pontianak. Berdasarkan data yang dapatkan, diperoleh hasil uji t sebesar 0,487 dan setelah dikonsultasikan dengan nilai t pada taraf signifikansi 5\% dan 1\% dengan db sebesar 58 pada taraf signifikansi 5\% sebesar 2,01 dan pada taraf signifikansi $1 \%$ sebesar 2,68, dan ternyata diketahui bahwa hasil t hitung lebih kecil daripada nilai $\mathrm{t}$ tabel. Hal ini berarti Hipotesa Alternatif (Ha) yang berbunyi "ada pengaruh antara tingkat pendidikan formal orang tua terhadap prestasi belajar mahasiswa/i program studi bimbingan dan konseling semester III tahun akademik 2014/2015" ditolak dan Hipotesa Nihil (Ho) yang berbunyi "tidak ada pengaruh antara tingkat pendidikan formal orang tua terhadap prestasi belajar mahasiswa/i program studi bimbingan dan konseling semester III tahun akademik 2014/2015" diterima. Dalam pengertian bahwa tidak ada perbedaan dalam prestasi belajar antara mahasiswa/i yang tingkat pendidikan orang tuanya SMA dengan mahasiswa/i yang tingkat pendidikan orang tuanya SD.

\section{DAFTAR PUSTAKA}

Ahmadi, Abu dan Nur Uhbiyati. (1991). Ilmu Pendidikan. Jakarta: Rineka Cipta.

Ahmadi, Abu dan Widodo Supriyono. (1991). Psikologi Belajar. Solo: Rineka Cipta.

Akbar, M. A. (2015). Peran Orang Tua Terhadap Pendidikan Anak (Studi Empiris Pada Komunitas Pedagang Kaki Lima Di Alun-Alun Kaliwungu Kecamatan Kaliwungu Kabupaten Kendal) (Doctoral dissertation, Universitas Negeri Semarang).

Azra, Azyurmadi. (1999). Esai-esai Pendidikan Islam. Jakarta: Logos.

Bahri Djamarah, Syaiful. (1994). Prestasi Belajar dan Kompetensi Guru. Surabaya: Usaha Nasional.

Budi, B. S. (2014). Strategi Guru Dalam Menghadapi Kurikulum 2013 Di SMA Negeri 2 Surakarta. Sosialitas; Jurnal Ilmiah Pend. Sos Ant, 4(1).

Departemen Pendidikan dan Kebudayaan. (1999). Kamus Besar Bahasa Indonesia. Jakarta: Balai Pustaka.

Depdiknas. (2003). UURI No 20 Th 2003 Tentang SISDIKNAS. Jakarta.

Eko Susilo, Madyo, R.B, Kasihadi. (1990). Dasar-dasar Pendidikan. Semarang: Effhar Publishing.

Enoch, M. Yusuf. (1995). Administrasi dan Supurvisi Pendidikan. Jakarta: IKIP.

Gunarsa, S. D. (2008). Psikologi perkembangan anak dan remaja. BPK Gunung Mulia.

Gunawan, H. (2012). Pendidikan Karakter. Konsep dan Implementasi, Cetakan ke-2, Alfabeta, Bandung.

Hamzah, N. (2015). Pendidikan Agama dalam Keluarga. At-Turats, 9(2).

Hasbullah. (1999). Dasar-dasar Ilmu Pendidikan. Jakarta: Raja Grafindo Persada.

Herman, T. (2007). Pembelajaran Berbasis Masalah untuk Meningkatkan Kemampuan Berpikir Matematis Tingkat Tinggi Siswa Sekolah Menengah Pertama. Educationist, 1(1), pp-47.

Himpunan Peraturan Perundang-undangan Tentang Guru dan Dosen. 2006. Bandung: Fokusmedia Idris, Zahara. (1995). Pendidikan dan Keluarga. Jakarta: Raja Grafindo.

Indonesia, P. R. (2003). Undang-Undang Republik Indonesia Nomor 20 Tahun 2003 Tentang Sistem Pendidikan Nasional.

Mawarsih, S. E., \& Hamidi, N. (2013). Pengaruh Perhatian Orang Tua dan Motivasi Belajar terhadap Prestasi Belajar Siswa SMA Negeri Jumapolo. Jupe-Jurnal Pendidikan Ekonomi, 1(3). 
Mulyani, E. (2012). Model Pendidikan Kewirausahaan di Pendidikan Dasar dan Menengah. Jurnal Ekonomi \& Pendidikan, $8(1)$.

Nasional, D. P. (2003). Sistem pendidikan nasional. Jakarta (ID): Depdiknas.

Purwanto, M. Ngalim. (2004). Psikologi Pendidikan. Bandung: Remaja Rosdakarya.

Sabri, H.M. Alisuf. (1996). Psikologi Pendidikan, Jakarta: Pedoman Ilmu Jaya.

Slameto. (1995). Belajar dan Faktor-faktor yang Mempengaruhinya. Jakarta: Rineka Cipta.

Suryoputro, A., Ford, N. J., \& Shaluhiyah, Z. (2006). Faktor-faktor yang mempengaruhi perilaku seksual remaja di jawa tengah: implikasinya terhadap kebijakan dan layanan kesehatan seksual dan reproduksi. Makara kesehatan, 10(1), 29-40.

Wildayati, I. A. (2012). Pengaruh Tingkat Pendidikan Formal Orang Tua terhadap Prestasi Belajar Studi PAI di SMP Negeri 1 Ambarawa Kab. Semarang Tahun Ajaran 2011/2012 (Doctoral dissertation, IAIN Walisongo).

Winkel, W.S. (1996). Psikologi Pengajaran. Jakarta: Grasindo.

Wirawan Sarwono, Sarlito. (2000). Pengantar Umum Psikologi. Jakarta: Bulan Bintang. 